Portland State University

PDXScholar

\title{
The validity of the Leiter international performance scale in measuring the intelligence of normal, borderline, and mentally deficient children
}

Marlin Pezner

Portland State University

Follow this and additional works at: https://pdxscholar.library.pdx.edu/open_access_etds

Part of the Child Psychology Commons, Mental and Social Health Commons, and the School Psychology Commons

Let us know how access to this document benefits you.

\section{Recommended Citation}

Pezner, Marlin, "The validity of the Leiter international performance scale in measuring the intelligence of normal, borderline, and mentally deficient children" (1980). Dissertations and Theses. Paper 2973. https://doi.org/10.15760/etd.2973

This Thesis is brought to you for free and open access. It has been accepted for inclusion in Dissertations and Theses by an authorized administrator of PDXScholar. Please contact us if we can make this document more accessible: pdxscholar@pdx.edu. 
AN ABSTRACT OF THE THESIS OF Marlin Pezner for the Master of Science in Psychology presented July 30, 1980.

Title: The Validity of the Leiter International Performance Scale in Measuring the Intelligence of Normal, Borderline, and Mentally Deficient Children

APPROVED BY MEMBERS OF THE THESIS COMMITTEE:

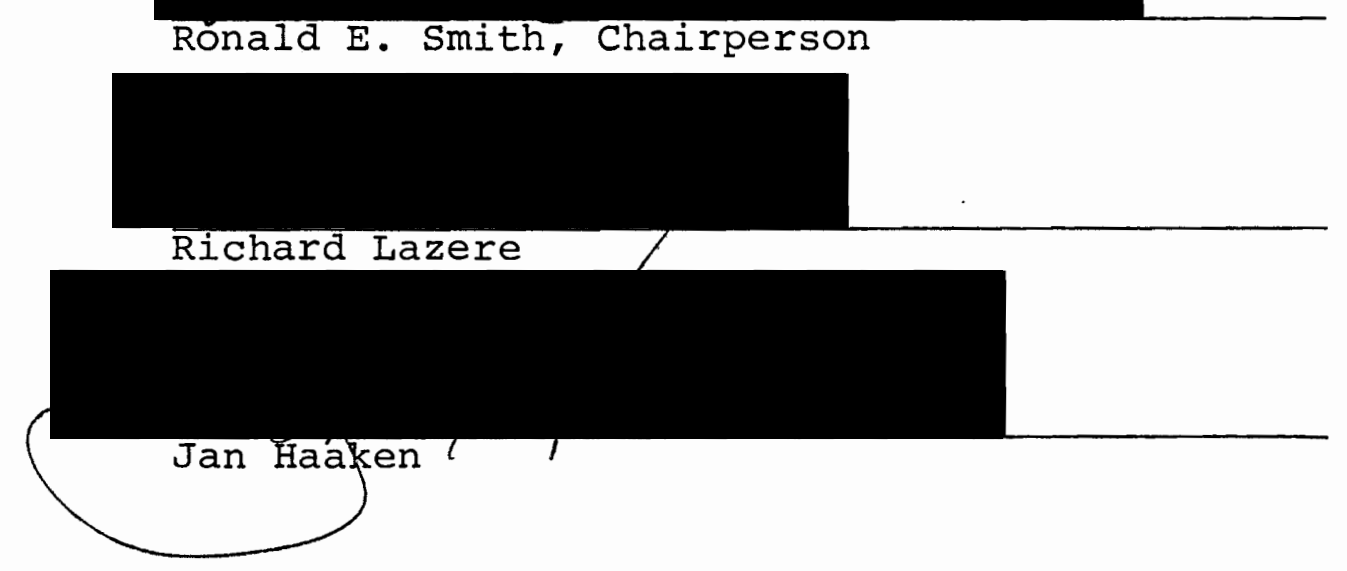

The purpose of this project was to compare IQ scores obtained using the Leiter International Performance Scale to those obtained using the Wechsler Intelligence Scale for Children-Revised (WISC-R).

A total of ninety-six subjects enrolled in public schools were used in this study. Of these, thirty scored in the "Normal" range, thirty-one scores in the "Borderline" range, and thirty-five scored in the "Mentally Deficient" 
range on the WISC-R. Pearson Product-Moment Correlation Coefficients were computed to determine the Leiter's degree of correlation with the WISC-R Verbal, Performance, and Full Scale Scores. Results of these computations indicated that the Leiter would be a valid assessment tool when used with "Normal" functioning children but does not appear to be valid when applied to "Borderline" or "Mentally Deficient" populations. Further calculations, however, yielded results that would indicate that the Leiter is able to distinguish between the three mental classifications approximately as well as the WISC-R.

Other conclusions about the Leiter were determined. The Leiter could not be found to be a useful substitute for the verbal or performance sections of the WISC-R. The abilities measured by the individual subtests could not be identified by the available data.

of interest was the indication that the Leiter correlated most highly with the WISC-R when the WISC-R Verbal IQ and Performance IQ scores approached a difference of 16-20, points. In view of the fact that an unusually high number of students had WISC-R Verbal and Performance IQ scores that were divergent by several points, it might be concluded that the Leiter may prove to be a valuable tool in the measurement of those disorders that would cause such VerbalPerformance score discrepancies.

It is hoped that this study will encourage other 
studies of the Leiter and its application with children enrolled in public schools. 
THE VALIDITY OF THE LEITER INTERNATIONAL PERFORMANCE SCALE IN MEASURING THE INTELLIGENCE OF NORMAL, BORDERLINE, AND MENTALLY DEFICIENT CHILDREN

$$
\text { by }
$$

MARLIN DEBRA HOPP PEZNER

\begin{abstract}
A thesis submitted in partial fulfillment of the requirements for the degree of
\end{abstract}

\author{
MASTER OF SCIENCE \\ in \\ PSYCHOLOGY
}

Portland state University 
TO THE OFFICE OF GRADUATE STUDIES AND RESEARCH:

The members of the Committee approve the thesis of Marlin Debra Hopp Pezner presented July 30, 1980.

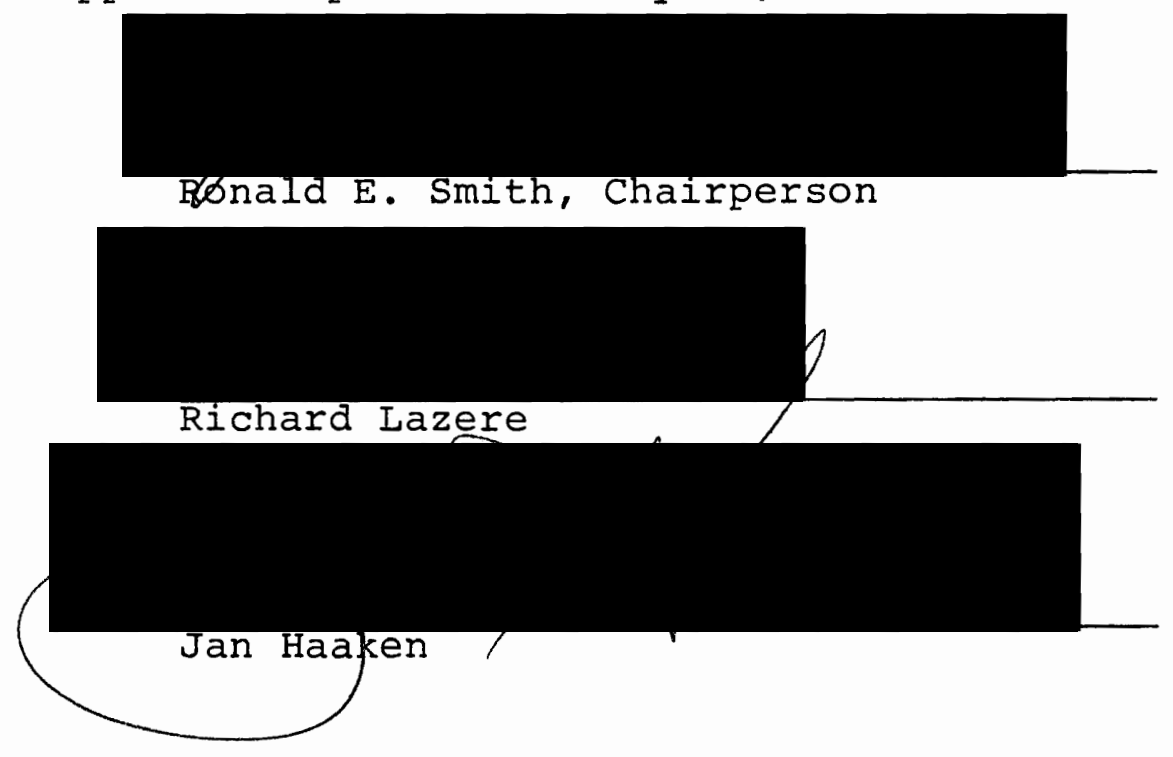

APPROVED :
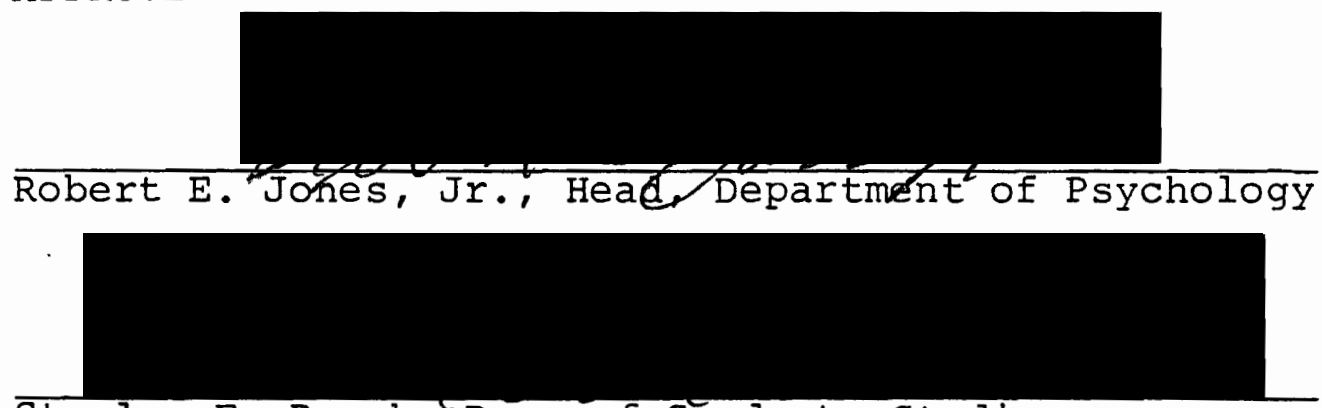

Stanley E. Rauch, Dean of Graduate Studies 


\section{ACKNOWLEDGMENTS}

The author wishes to express her gratitude and appreciation to the people of the Oregon City and Evergreen School Districts for their help and friendship. Particular thanks are due to Eugene Bates, Director of Special Services, Oregon City, Oregon without whose cooperation and generosity this project would never have been completed.

Many thanks are owing to Ron Smith, Richard Lazere, Walter Klopfer, and Jan Haaken whose cooperation and guidance have far exceeded the call of duty.

The author extends warm thanks to Georgene Inaba and Susan Paltrow for their technical assistance, and, more importantly, their loving friendship.

Special thanks go to my dear friend, Stephanie Ritzert and to my husband, Richard Pezner. Without Stephanie's faith, love, and encouragement this paper would have never been finished. And without Rich's love and support this paper would never have been worth doing. 
TABLE OF CONTENTS

PAGE

ACKNOWLEDGMENTS

LIST OF TABLES

LIST OF FIGURES

CHAPTER

I INTRODUCTION . . . . . . . . . . . . . 1

Hypotheses . . . . . . . . . 2

D. Definition of Intelligence . . . . . . 4

Mental Classification Systems . . . . 4

$\pi$ Description of the Leiter International Performance Scale . . . . . .

Leiter Standardization . . . . . . . 8

Discussion of Weaknesses of the Leiter... . . . . . . .

The Wechsler Intelligence Scale for Children-Revised . . . . . .

II REVIEW OF RELEVANT LITERATURE • • • • •

Development of the Leiter . . . . . 14

Review of Relevant Studies . . . . . 16

III METHOD . . . . . . . . . . . . . 28

Selection of subjects . . . . . . 28

Procedure ..... . . . . . . 29

Limitations of the Study . . . . . . 30 
CHAPTER

PAGE

IV

RESUITS

Analysis of Subject Data . • • • • •

Analysis of Test Data • • • • • • •

32

V CONCLUSIONS AND RECOMMENDATIONS • • • • •

Discussion of the Results $\cdot$. $\cdot$ - $\cdot$ •

Conclusions . • • • • • • • • • • • •

Suggested Areas for Further

BIBLIOGRAPHY 


\section{LIST OF TABLES}

TABIE

PAGE

I WISC/WISC-R Comparison Studies . . . . . • .

I Validity Studies of the Leiter

International Performance Scale . . . .

III Grade Distribution . . . . . . . . . . .

IV Age Distribution . . . . . . . . . . . .

V Male-Female Proportions . . . . . . . . .

VI Distribution of Male-Female Subjects

Per Grade . . . . . . . . . . . . .

VII Correlation Between WISC-R and Leiter

Entire Sample . . . . . . . . . . .

VIII Correlation Between WISC-R and Leiter

Normal Sample Only . • . • . • • • .

IX Correlation Between WISC-R and Leiter

Borderline Sample . . . . . . . . . .

X Correlation Between WISC-R and Leiter

Mentally Deficient Sample . . . . . . .

XI Analysis of Variance of WISC-R and Leiter

Means for Each Mental Classification . .

XII WISC-R - Point Difference Between

Verbal and Performance IQs Per

Mental Classification . . . . . . . . 
XIII Correlations Between WISC-R and Leiter

Taking Into Account Point Differences

Between WISC-R Verbal and Performance

Scores • • • • . . • • • • • • • •

XIV Correlation of Leiter to WISC-R For

Subjects with Verbal-Performance

Discrepancy • • • • • • • • • • • • •

XV Point Differences Between Verbal and

Performance IQs - Male/Female

Differentiation . • . . . . . • • • .

XVI Effect of Sex and Mental Classification

on WISC-R FSIQ, VIQ, PIQ, and

Leiter Scores . . . . . . . . • • 


\section{LIST OF FIGURES}

FIGURE

PAGE

1. Graph of correlations between WISC-R and

Leiter based on point differences between

the WISC-R verbal and performance scores. .

55 
CHAPTER I

\section{INTRODUCTION}

With the development of numerous social and government programs designed to provide educational opportunities to children of all levels of intellectual functioning, the use of a wider variety of assessment tools has become necessary. The Wechsler Intelligence Scale for Children-Revised (WISC-R) is the current standard for intelligence testing. However, for certain children, the WISC-R, as well as many of the other verbal-type tests currently used, would not provide accurate assessment due to limitations inherent in the test itself and/or due to the child's own limitations. Many practitioners have therefore begun investigating the use of performance scales as an alternative to currently used tests.

The Leiter International Performance Scale is a performance test of intellectual functioning which was introduced in 1940 (Leiter, 1940). Several studies indicate that the Leiter may have potential value in assessing many of those children for whom the WISC-R and other tests may be inappropriate. These children include those who have cerebral palsy (Arnold, 1951), hearing and/or language disorders (Birch \& Matthews, 1949; Mira, 1962), or who 
may be mentally deficient (Bensberg \& Sloan, 1951; Gallagher, Boyd, \& Benoit, 1956; Hunt, 1961). The Leiter also appears to have value when assessing children who are normal (Arthur, 1952; Leiter, 1936, 1950), superior functioning (Peisner, 1956), non-English speaking (Cooper, 1958), or from minority groups (Clegg \& White, 1966).

Little has been done in the way of recent research on the Leiter. Although there have been previous studies in which the Leiter has been compared to the Stanford-Binet Intelligence Scale and the Wechsler Intelligence Scale for Children (WISC), no new research has been done since the revised version of the WISC--the WISC-R--was introduced in 1974. If the Leiter is to be used for the same purpose as the Wechsler Intelligence Scale for Children-Revised, then it is reasonable to expect it to have concurrent validity. Consequently, the purpose of this study is to examine the validity of the Leiter International Performance Scale as compared to the WISC-R.

\section{Hypotheses}

Hypotheses that were tested in this study are stated as follows:

1. The degree of relationship between the Leiter International Performance Scale and the wechsler Intelligence Scale for Children-Revised Full Scale IQ is moderately high to high and positive.

2. The degree of relationship between the Leiter 
International Performance Scale IQ and Wechsler Intelligence Scale for Children-Revised Verbal IQ is moderately high to high and positive.

3. The degree of relationship between the Leiter International Performance Scale IQ and Wechsler Intelligence Scale for Children-Revised Performance IQ is moderately high to high and positive.

Questions that were explored in this study included the following:

1. Is the Leiter a valid test when assessing a normal population?

2. Is the Leiter a valid test when assessing a borderline population?

3. Is the Leiter a valid test when assessing a mentally deficient population?

4. Can the Leiter be used as a substitute for the WISC-R?

5. Can the Leiter be used as a substitute for the verbal and/or performance sections of the WISC-R?

6. Does the Leiter yield information that would make it a valuable supplement to the WISC-R?

7. What abilities do the individual subtests on the Leitèr measure?

8. Do some of the subtests on the Leiter need to be revised or eliminated? 
Definition of Intelligence

The question of the nature of intelligence has long been a subject of controversy for professionals and laymen alike. Definitions of this concept have ranged from "the innate capacity of the individual, his genetic equipment" to "an individual's observed behavior" to "whatever the results on an intelligence test happen to be" (Sattler, 1974, p. 8). Certainly defining intelligence is not an easy task.

Wechsler addresses the definition of "intelligence" in the following way:

Intelligence is the overall capacity of an individual to understand and cope with the world around him. It conceives of intelligence as an overall or global entity; that is, a multi-determined and multifaceted entity rather than an independent, uniquely defined trait. . . . It avoids singling out any ability, however esteemed (e.g., abstract reasoning) as crucial or overwhelmingly important. In particular, it avoids equating general intelligence with intellectual ability. (p. 5)

Leiter (1940), however, has identified intelligence as being primarily a problem-solving ability that determines an individual's ability to cope effectively with new experiences.

Mental Classification Systems

Systems for classifying levels of intellectual ability have been in existence for approximately 75 years since the introduction of the Metrical Scale of Intelligence of Simon and Binet (Sattler, 1974). Tests designed to make distinctions between various levels of intelligence, so-called 
intelligence tests, have been widely used and have significantly influenced many aspects of contemporary life. Examples of their usage range from the development of educational programs to job applicant screening. Because of the great influence of intellectual testing in our society, a closer examination of the application of derived mental classifications is needed.

Mental deficiency. The terms mentally retarded, mentally defective, mentally deficient, and feeble minded have all been applied to those individuals whose level of cognitive functioning is less developed and sophisticated than the majority of others in the same chronological age group.

Sattler (1974) points out that Binet and Simon distinguished retarded intellectual functioning from normal functioning by three components that acted together to form a single process:

direction of thought (its complexity and persistence), adaptation (ability to differentiate) and selfcriticism. (p. 92)

Sattler goes on to discuss these components as follows: These three elements may be paraphrased as follows: a) the ability to take and maintain a given mental set; b) the capacity to make adaptations for the purpose of attaining a desired end; and c) the power of anticriticism. These elements were also included in a functional definition of thought. Although Binet and Simon did not have a well-formulated definition of intelligence, no earlier definition was as concise in emphasizing the active and organized properties of intelligence. (p. 92) 
The American Association of Mental Deficiency defines

mental retardation as:

subaverage general intellectual functioning which originates during the developmental period and is associated with impairment in adaptive behavior. (Matarazzo, 1974, pp. 141-142)

Normal. While the term normal has been applied by Binet to indicate those persons whose mental age is roughly commensurate with or better than their chronological age, Wechsler merely indicates normalcy by means of a bell-shaped curve. The area of normalcy falls between mental deficiency and very superior and clearly accounts for the vast majority of the population. This is determined by taking the mean of the test $(100) \pm 2$ standard deviations (15).

Borderline. The classification of borderline is designated by Wechsler as between mentally deficient and normal and theoretically identifies persons who score between 2 and 3 standard deviations below the mean of his test.

Description of the Leiter International Performance Scale

The Leiter International Performance Scale is a performance test of intellectual functioning which was introduced in 1939. Since then it has undergone several revisions, the most recent being in 1948 (Leiter, 1950). Its original purpose was to serve as a substitute for, or supplement to, verbal-type scales such as the Stanford-Binet Intelligence Scale. 
Unlike many intelligence tests the Leiter is primarily non-verbal. Instructions by the examiner are pantomimed. Direct questions from the subject are handled in the simplest and least directive manner by the examiner.

Leiter (1940) felt that the advantages of his test over other tests were:

1. simple administration

2. complete objectivity in scoring

3. minimization of environmental factors by eliminating verbal interaction between subject and examiner

4. use of novel material.

Other factors that may be advantageous are the eliminations of time limits and the simplicity of the basic task (that is, putting the blocks in a frame). Leiter went on to indicate the potential cross-cultural applicability of the tests through the simple changing of certain culturespecific pictures. (E.g., in Test III-3 where the child must match two halves of a costume, costumes indigenous to a region might be substituted.)

In its current form, the Leiter consists of 54 subtests arranged by age level. Each subtest is represented by a cardboard strip and a corresponding set of blocks. Both the strips and blocks have pictures that, in some way, correspond to one another. The strip is placed in a wooden frame before the subject. The blocks are then presented in a prescribed order. The subject is required to deduce the 
correct association between each block and each picture on the strip and then to place the blocks in notches in the frame in proper positions. The examiner then determines whether or not the solution is correct. Credit is given only for the correct answer. No partial credit is given. Basal and ceiling ages are obtained in addition to intelligence quotients and mental age equivalents.

\section{Leiter Standardization}

The author was unable to obtain Leiter's dissertation entitled "A Comparative study of the General Intelligence of Caucasian, Chinese, and Japanese Children As Measured By the Leiter International Performance Scale" (1938). Since little has been written about Leiter's rationale and methodology for development and standardization of his test, the following excerpt from a thesis entitled "A Clinical Examination of the Leiter International Performance Scale" by R. W. Williams (1941) may shed some light on Leiter's methods. It should be noted that Leiter originally standardized his test using school children in Hawaii. It was not until much later that the test was standardized for use with Caucasians.

\section{Hawaiian Standardization}

The reliability of the scale was tested by the standard deviations of the distributions for each age level and by the coefficient of reliability determined by the split-half method. The standard deviations for the age levels range from 8.7 to 15.8 points of $I Q$ and $a$ standard deviation for the total group was 13.2. deviations show less scatter and presumably more 
reliability than those obtained by the Revised stanfordBinet scale. (The standard deviation of the Revised Stanford-Binet scale ranged from 12.5 to 20.6 on Form L and from 13.2 to 20.7 on form $M$. The standard deviation of the composite L-M IQ's for the total group was 16.4.) The coefficient of reliability, determined by the splithalf method was $.88 \pm .0058$. By applying the spearmanBrown formula, the corresponding $r$ for the full length of the test was found to be .93.

The validity of the scale was verified by the increase in mental age from one chronological age group to the next and by a normal distribution of IQ's for the entire group, the distribution at each age level, owing to the limitation of the number of cases, only roughly approximating the normal curve. The correlation with teachers' judgements was only .32 but the author felt that the judges were not competent. This belief was substantiated by the fact that the distribution of test scores was more in accordance with present knowledge of biological trait distributions than were the judgements of the teachers. The validity of the individual test items was judged by two criteria: 1) Increase in proportion of passes from one year to the next, and 2) A higher proportion of passes by those children who were rated high on the entire scale.

\section{Caucasian Standardization}

The caucasian standardization was made in the city of Los Angeles on 35 children at each year level from five to twelve. A re-organization of the scale as prepared for Oriental children was found necessary. Again, the tests were placed so as to obtain an average mental age approximately equal to the chronological age of each year group. In this standardization a reliability coefficient of $.89 \pm .004$ was established by the split-half method using mental ages as before. This reliability was raised to .94 by the Spearman-Brown formula.

Validity was established by the increase in mental age from one age group to the next; by the fact of an approximately normal distribution of IQ's at each age level and for the whole group; by a correlation of .48 with teachers' judgements, and by a correlation with the Goodenough Drawing Test of $.83 \pm .003$. The individual test items met the criteria of validity established for the original standardization of the Leiter tests on the groups of oriental children. (pp. 7-9) 
Discussion of Weaknesses of the Leiter

Matthews and Birch (1949) evaluated the Leiter from a practical application viewpoint. Suggested possible weaknesses of the test which appear to require more research are:

1. Information on it's validity is inadequate for both normal and handicapped subjects (p. 319).

2. The reliability of the scale has not yet been sufficiently studied (p. 319).

3. Many of the subtests required color discrimination. The effect of aberrations in color vision has not yet been investigated thoroughly (p. 320).

4. Certain subtests require recognition of pictures of common objects. Cultural deprivation or a specific physical handicap (e.g., deafness) might invalidate the test assumption that these objects are common knowledge, thus putting the child at a disadvantage (p. 320).

5. Many of the subtests require construction of block-patterns, or require the ability to see analogic relationships between one set of line drawings and another. Brain-damaged subjects often have difficulty with these. Evaluation of the tests with brain-damaged subjects is needed (p. 320).

6. Modifications of the techniques are made for applying the Leiter to chilaren with cerebral palsy. Such modifications need to be noted and standardized (p. 320). Although Sattler points out that the Leiter can be an 
aid in clinical diagnosis (particularly with certain handicapped children), Werner (1965) characterizes problems with the Leiter as follows:

Item difficulty levels may be uneven; certain pictures are outdated; the culture fairness of the scale has not been determined; the abilities measured by the scale are not clear; and the scale contains a small number of tests at each year level. ( $p$. 815)

The Wechsler Intelligence Scale

for Children-Revised

Since its introduction in 1974 the Wechsler Intelligence Scale for Children-Revised has become one of the most widely used tools for assessing intelligence at all levels of functioning. Although the WISC-R and its predecessor, the WISC, are structurally similar, comparability studies of the two reflect many differences. The most important difference appears to be in the area of obtained IQ score, although differences in item specificity, administration, and scoring are also evident. Studies by such authors as Hamm (1978), Kaufman and Van Hagen (1975), and Bloom, Raskin, and Reese (1976) all indicate high correlations between the WISC-R and the WISC, ranging from +0.85 to +0.90 .

Studies which concentrate on the differences in IQ scores are summarized in Table I. These studies note differences in IQ points ranging from 2.1 (Zimmerman, 1976) to 9.4 (Larrabee \& Holroyd, 1976) for full scale scores. All studies clearly reflect that the WISC-R yielded lower IQ 
TABLE I

WISC/WISC-R COMPARISON STUDIES

Researcher

Sample

Zimmerman (1976)

Swerdik \& Rice (1975)

Hamm et al.

(1976)

Kaufman \& Weiner (1976)

Solway et al.

(1976)

Larrabee \& Holroyd (1976)

Schwarting

(1976)

EMR
WISC minus WISC-R

Differences

(in points)

VIQ

PIQ

FSIQ

$E H$ and EMR

Students

EMR and

nON-EMR

LOW SES

Black Children

Juvenile

Delinquents

High Ability

Randomly

selected

children
$9.6 \quad 8.4$

9.4

EH Students :

$4.9 \quad 3.0 \quad 4.1$

EMR Students:

$\begin{array}{lll}3.3 & 2.2 & 2.1\end{array}$

$\begin{array}{lll}3.80 & 2.74 & 3.05\end{array}$

$6.0 \quad 10.0 \quad 7.5$

$\begin{array}{lll}7.0 & 8.0 & 8.0\end{array}$

$2.35 \quad 3.67 \quad 3.05$

$\begin{array}{lll}4.86 & 8.74 & 7.49\end{array}$

Note: In all cases, IQ scores obtained on the WISC-R were lower than IQ scores obtained on the WISC. 
scores than the WISC. These results have significance in terms of the many children who might be classified in a lower intellectual category based on the administration of the WISC-R as opposed to the WISC. Iittle is needed to imagine the possible ramifications of such a classification in terms of social and educational programs provided. 
CHAPTER II

\section{REVIEW OF RELEVANT LITERATURE}

\section{Development of the Leiter}

Leiter developed his test as an extension of work done by Stanley D. Porteus (Leiter, 1940). Leiter's first test was devised in 1927 and was used with children who were "feeble-minded." It's purpose was "to measure intelligence by memory and rate of learning" (Leiter, 1936, p. 3). Subjects were scored on the basis of the amount of improvement over initial trials within the restrictions of a time limit.

Leiter soon found that "these tests of memory and learning were insufficient in themselves for measuring intelligence" $(1936$, p. 3). Changes in the test resulted in a revised scale which had twelve different tests. Investigations showed the new tests to be sampling many of the functions measured by the Stanford-Binet Scale. More revisions were made.

As noted earlier, the test was then standardized in Hawaii using a population of Oriental children enrolled in elementary and intermediate schools. Further revision, including the incorporation of Grace Arthur's adaptation of the Leiter (to be discussed later), resulted in the test's present form. 
Leiter does not identify the definition of intelligence upon which he bases his test. He indicates, without specific reference to other known studies, that measurement of "mental capacity" in children under the age of four is probably unreliable while going on to add that:

There is every reason to believe that there is not as much mental development after the twelfth year as some have been inclined to think. . . . In addition, evidence has been accumulating from various sources which seems to indicate that there is no such thing as general intelligence after the twelve- or thirteen-year level. (1936, p. 4)

In a later work, however, he states that:

While the tests of the scale are in no way modifications or adaptations of the Binet test they may be considered of equal value, year level for year level, since they were standardized and located in the scale in exactly the same manner as were the tests of the Binet Scale. Therefore, the intelligence quotient obtained from the application of this scale is subject to the same interpretation as the intelligence quotient secured from the application of the Binet Scale. However, it must not be assumed that the intelligence quotients of the two scales are exactly comparable because whereas the Binet Scale follows the theory that the amount of information children pick up through incidental learning is a good index of brightness, the Leiter International Performance Scale is built on the principle that children's ability to cope with entirely new situations is a truer indication of their general intelligence. (1936, p. 10)

No discussion of the current form of the Leiter International Performance scale would be complete without mention of the Arthur Adaptation of the Leiter International Performance Scale (Arthur, 1952). Arthur had been working on a point scale of performance test. She stated that

The need for re-standardization of the original (1940) Leiter scale was felt when it became evident that the Leiter norms for 'Caucasian' children were too high to 
enable the average middle class American child to earn a score that represented his level of ability.

Arthur then proceeded to combine her own scale with the Leiter. She changed the scoring system, dropped some items, and repositioned others. The age range of the test was limited from three to eight years. All tests beyond 12.4 were eliminated. However, as pointed out by Glenn (1951) :

By neglecting to take into account acquired skills, and by weighing the performance factors so heavily, Arthur has overlooked or discarded the main objective for which the Leiter International Performance Scale was constructed. She is making this test an extension downward of her Form I of the point scale of performance tests. Used in this manner it will give a performance rating on the child rather than an estimation of how he would function on a verbal test such as the Binet, if it were possible to give him a Binet. This is assuming the Leiter and the Binet measure one type and the Arthur a different sort of ability. Thus, children with poor motor coordination, such as spastics, would be unduly penalized by the heavy weighing given performance ability when Form II of the Arthur is used in conjunction with the Leiter. (p. 7)

Leiter acknowledged the improvements made by Arthur in her adaptation. In his final 1948 revision, Leiter incorporated all of Arthur's suggestions into his own test, thus creating the current Leiter International Performance Scale.

Review of Relevant Studies

Relatively few studies of the Leiter have been undertaken since its introduction in 1948. Most have been in the areas of measurement with mentally deficient; speech, language, or hearing impaired; or non-English speaking 
children. Other studies have concerned themselves with the effects of various factors on test performance or the Leiter's use with handicapped populations such as the cerebral palsied. The results of those few tests, in which the Leiter's validity was examined, are summarized in Table II and discussed later.

In a study of ninety mentally retarded children enrolled in a state school for the retarded, Hunt (1961) first divided her subjects into the following classification:

1) Retarded diagnosed as Familial. 2) Brain-injured with no medically recognized loss of visual acuity or who were classified as being handicapped with regards to visual-motor activities, tasks of visual discrimination, or responding to two-dimensional materials, 3) Brain injured children with no medically recognized loss in visual acuity with no minimal handicaps in responding to visual-motor activities, tasks of visual discrimination, and/or in gaining meaning from twodimensional materials. (pp. 99-102)

Both the Leiter International Performance Scale and the Stanford-Binet were administered. Results of statistical analysis indicated that there was no significant difference by the mean scores between children diagnosed as the Familial and the other two brain-injured groups. Additionally, there was no significant difference in response to visual-motor activities between those children with minimal visual handicaps who have no recognizable loss in visual activity and those children with no loss of visual acuity who had been classified as handicapped. Also, the authors indicated that there was a high positive relationship between performance on the Leiter and the mental age 
TABLE II

VALIDITY STUDIES OF THE LEITER INTERNATIONAL PERFORMANCE SCALE

Researcher Tests Used

Sample

Correlation

Tate

(1950)

LIPS VS.

Preschoolers

$+.81$

Beverly \&

Stanford-Binet

Bensberg

LIPS vS.

Mental Deficients

$+.62$

(1952)

Glenn

(1951)

LIPS vS.

White, Middle Class

$+.77$

Stanford-Binet children

Cooper

LIPS VS.

Bilingual pupils in

$+.83$

(1958)

WISC

Guam

Sharp

LIPS VS .

Slow Learners

$+.84$

(1958)

WISC 
obtained on the Stanford-Binet although no specific statistical information was provided with regards to the subject. Beverly and Bensberg (1952) administered the Leiter, Binet, and the Cornell-Coxe (a performance test) to fifty mental defectives from a state hospital. Ages of the subjects ranged from six years eleven months to sixteen years two months. Correlations between the Leiter and the Cornell-Coxe and the Leiter and Binet were 0.82 and 0.62 respectively. The authors indicated that the Leiter did not appear to be a more valid instrument for this population than the Cornell-Coxe when compared to the Binet. Also, the authors suggested that new norms for mental defectives appeared to be needed.

Gallagher, Benoit, and Boyd (1956) compared the Columbia Mental Maturity Scale (CMMS) with the Leiter and the Stanford-Binet for use with the population of braindamaged children. Forty children from a state school were tested. Their ages ranged from seven years four months to thirteen years ten months. Correlations among the three tests were as follows:

$$
\begin{aligned}
& \text { Binet versus CMMS }=0.93 \\
& \text { Binet versus Leiter }=0.86 \\
& \text { CMMS versus Binet }=0.85
\end{aligned}
$$

It was found that the means of all three tests differed significantly from each other. The authors concluded that the tests were not comparable with their population. 
They found this to be particularly true of the Leiter when used on children below a Binet mental level of 4-1/2 years. In a comparison of the Leiter and Stanford-Binet, Evans (1954) tested 131 mentally retarded children enrolled in a state training school. Correlations between the two tests for IQ were 0.78 and 0.76 for subjects between five and ten years of age and eleven through thirteen years of age respectively. Correlations for subjects fourteen through fifteen years was 0.68 . For subjects over sixteen years, a correlation of 0.53 was yielded.

Evans went on to find that there was a significant difference of three points between the average means of the two tests. This difference was small for the younger age groups and increased with the older groups.

In a study of the Leiter and Stanford-Binet, Robert Glenn (1951) tested fifty-three children with normal intelligence enrolled in public schools who had been given the Stanford-Binet at the age of six. Statistical analysis yielded a correlation coefficient of 0.77 between the two tests (significant at the one percent level). Glenn suggested that the Leiter may be used with assurance in differentiating mentally deficient from normal children but may not sufficiently differentiate between normal and above normal intelligence.

Based on regression equations, Glenn determined that the Leiter "seems to measure consistently low in below 
average and average ranges but is unpredictable in the above average ranges" (p. 26). However, Glenn did not actually use subjects whose scores were specifically classifiable as mentally deficient or superior, thus showing no supportive foundation for his assumption.

Cooper (1958) used the Leiter in his study of fiftyone bilingual fifth grade students in Guam. The purpose of the study was to determine the predictive value of six tests of intelligence: California test of mental maturity, DavisEels Games, the Culture-Free Intelligence Test, the Leiter International Intelligence Performance Scale, the wechsler Intelligence Scale for Children, and the Columbia Mental Maturity Scale. Correlations between the Leiter and other tests are as follows:

Leiter Vs. WISC

$\begin{array}{ll}\text { Full } & 0.83 \\ \text { Verbal } & 0.73 \\ \text { Performance } & 0.78\end{array}$

Leiter vs. California Test of Mental Maturity

\begin{tabular}{cc} 
Total IQ & 0.68 \\
Language & 0.62 \\
Non-Language & 0.66 \\
& \\
Leiter vs. Davis-Eels $=0.72$ \\
\hline
\end{tabular}

Culture-Free Intelligence Test Raw Score vs. Leiter $=0.75$ Columbia Mental Maturity Scale vs. Leiter $=0.69$

As compared to later school achievement tests and teacher ratings, the Leiter correlated positively and moderately high. Correlation coefficients for the six 
intelligence tests and the California Achievement Test are:

Davis Eels Game

Culture-Free Test

Columbia Mental Maturity Scale

California Test of Mental Maturity

Leiter International Performance Scale

Wechsler Intelligence Scale for Children full scale

$$
\begin{aligned}
& =0.53 \\
& =0.55 \\
& =0.61 \\
& =0.64 \\
& =0.66 \\
& =0.77
\end{aligned}
$$

Sharp (1958) compared the Leiter to both the WISC and Stanford-Binet using a population of fifty slow learning children drawn from public schools. All but one subject scored an IQ of 75 or less on the Stanford-Binet. Correlations for the Leiter and other tests were as follows: Leiter vs. WISC

$\begin{array}{cr}\text { Full Scale } & 0.83 \\ \text { Verbal } & 0.78 \\ \text { Performance } & 0.80 \\ \text { Leiter Vs. Stanford-Binet }\end{array}$

Sharp concluded that mental defectives tend to score higher on performance items than verbal items. Also, variation of scores increased with older subjects, thus suggesting that the Leiter norms for older mentally retarded children should be questioned.

The Leiter's use with certain handicapped populations has been explored. Arnold (1951) studied the Leiter's 
applicability to children with cerebral palsy. Twenty-five children with IQs between 90 and 110 on the revised Stanford-Binet (Form $L$ ) and twenty-five children with IQs between 50 and 70 on the revised Stanford-Binet (Form L) were tested with the Leiter and Porteus Mazes.

No children had apparent physical defects. Manipulation of the Leiter materials was performed by the examiner as per instructions from the subject. Correlation coefficients were computed for rank orders on each test and were as follows:

Test

Leiter vs. Binet Binet vs. Mazes Leiter vs. Mazes
Normal

$0.88 \pm 0.031$

$0.86 \pm 0.036$

$0.861 \pm 0.036$
Feebleminded

$0.94 \pm 0.015$

$0.81 \pm 0.047$

$0.861 \pm 0.036$

Arnold combined the scores on both the Leiter and Porteus Mazes and then correlated them with the StanfordBinet. She found a correlation of $0.870 \pm 0.025$ for the normal group and $0.905 \pm 0.033$ for the feebleminded group. She concluded that the adaptations in technique did not invalidate the Leiter or Mazes tests, and that both had a high index of reliability.

In a number of articles generated from their school in Pennsylvania, Birch, Birch, Matthews, et al. (1949, 1951, 1956, 1963) studied the predictions of school achievement and intelligence testing of their deaf students. They compared the Leiter to the Arthur point scale of performance test (Form 1), Hickey's Nebraska test of learning aptitude for 
young deaf children, the performance scale of Wechsler's Adult Intelligence Test (Form 1), and the Goodenough Drawing Test. They found that the Leiter yielded IQs generally lower than the other tests commonly used for the deaf. They go on to add that the Leiter appears to "reveal aspects of their mental structure not shown by other tests," although these "aspects" are not identified in their research.

Use of the Leiter in predicting school achievement in deaf students has apparent positive value. After evaluating thirty-five children immediately upon enrollment in their school, a prediction chart was formulated. After six months, and again after eleven years, teacher evaluations and the Stanford achievement tests were compiled. Both the sixmonth and eleven-year studies showed the Leiter to have good predictive validity. Correlation between the Leiter and prediction charts was 0.71 (at six months). Correlation between the Leiter and achievement tests (at eleven years) was 0.95 .

In a brief study of the validity of the Leiter, Bessent (1950) examined twenty people, primarily children, referred to court psychologists. Fifty percent of these subjects were of Mexican ancestry. Correlations between the Leiter and Stanford-Binet (Form L) were computed, yielding a coefficient of 0.92 .

A correlation of mental age yielded a coefficient of 0.93. The author points out that although the scores 
yielded by the Leiter and Stanford-Binet appear to be similar in magnitude, the large age range of the sample (age four through fifty-eight years) and small number may have had spurious effect on the results.

Clegg and white (1966) applied the Leiter to a population of 108 deaf Negro students enrolled in a residential school. All children were between six and fourteen years of age. A comparison of the mean IQs of the sixty-three males and forty-four females yielded no significant difference. This indicated no significant sex difference in general intelligence testing in a population.

In an interesting study of the influence of cultural factors on the Leiter, Tate (1952) divided 108 children between four and six years of age into groups depending upon parental, educational, and socio-economic levels. These groups were as follows:

Group 1: Professional pre-school group. Fathers of these pre-school children were all either of the professional or managerial occupation groups. Half held either a Ph.D. or an M.D. degree, and the mean educational level was 17.8 years. The mothers of this group averaged 15.5 years of education with seventeen holding Bachelor's degrees and an additional five with graduate degrees.

Groups 2 and 3: Kindergarten professional group and Kindergarten lower socio-economic group. The occupational and educational level of parents of the kindergarten 
professional group approximate those of the pre-school professional group. The fathers of the kindergarten lower socio-economic group ranged in occupation level from skilled tradesman (e.g., mechanics) to unskilled day-laborer.

Group 4: Orphanage group. These children were, for the most part, orphans and lived in a court-appointed home. They came from the poorest homes in the state, representing parental occupations ranging from semi-skilled labor to unemployed.

Each child was tested with the Leiter (original and revised version), the Arthur scale, and the Stanford-Binet (Form L). All tests differentiated between all groups except the professional pre-school and kindergarten professional group. There was no significant variance between the Stanford-Binet and Leiter scores. Significant variance between the Leiter and Arthur scores at the five percent level of confidence, however, was indicated. Other conclusions were that the Leiter appeared to be no more culturefree than the other tests, and that it correlated highly with the Stanford-Binet $( \pm 0.80)$.

Since the Leiter has no time restrictions, Wolf and Stroud (196I) examined the implication of the ability to respond on a test quickly as a measurement of intelligence. They examined 102 fifth-grade students with the Leiter, the Iowa Test of Basic Skills, the Lorge-Thorndike Intelligence Tests, and part of the Leiter Progressive Matrices. Some 
of the subjects were instructed to work as quickly as possible, with no time instructions. Median time scores were compared with overall scores on the test. Results seemed to indicate that those children who were able to perform "mental feats" more quickly tended to demonstrate more ability than their slower, but equally accurate counterparts. 
CHAPTER III

METHOD

Selection of Subjects

Subjects were obtained through two Portland area public school districts. The subjects were chosen by the districts on the basis of need for current assessment. Requirements for inclusion in this study were that:

1. The subject's age be within the limits established by the WISC-R.

2. The subject was able to respond appropriately on both the WISC-R and Leiter.

3. The subject had not been tested with an intelligence test for a minimum of two years.

Demographic characteristics of the sample--such as the age distribution and sex proportion--were determined by subject availability. Data on race and family SES was not available.

In this study, 108 subjects were tested. Of these, twelve were judged to be outside of the requirement guidelines. Of the twelve, five subjects were found to have been tested within the last two years and seven subjects scored so poorly on the WISC-R and/or Leiter that IQ and mental age equivalents could not be determined with any assurance of 
accuracy. Of the remaining ninety-six subjects, thirty scored within the "normal" range on the WISC-R $(80+)$, thirty-one scored within the "borderline" range (70-79), and thirty-five scored within the "mentally deficient" range (below 70). Proportion of male to female subjects is shown in Table $\mathrm{V}$ (see Appendix).

\section{Procedure}

Full disclosure as to the nature of the Leiter and WISC-R as well as the intended purposes of testing was made to each subject and his or her parents, or guardians, prior to testing. Each subject was tested individually in rooms in his or her own school. Testing conditions were optimal for each test session to insure the best possible performance by each subject. All children were examined by this author exclusively in order to minimize those factors that would be influenced by subject-examiner rapport or examiner bias in scoring.

Because of the amount of time required to set up the Leiter, the Leiter was routinely administered first. Instructions for administration, as written in the manual, were followed as closely as possible. Upon completion of the Leiter, each subject was given a rest period. Afterwards, the WISC-R was administered as per the instructions in its manual. After completing both tests the subjects returned to their classrooms. 


\section{Limitations of the Study}

The major limitations of this study is that the number of subjects in each mental classification group may be too small to yield statistically significant results that would be applicable to other similar groups of subjects.

Another serious limitation is the lack of background data on each subject. It was unknown whether any subjects had any visual and/or motor disturbances that would have affected their performance. Other factors such as SES and parent educational background that, undoubtedly, have a major influence on the subjects' development were not available for analysis.

Finally, one must consider the previous educational experiences of each subject. There were tremendous variations between the different school programs, not the least of which were policies and procedures used to place the children in their current class assignments. It was not possible to compensate for this great variation in the analysis of this study. 
CHAPTER IV

\section{RESULTS}

\section{Analysis of Subject Data}

of the ninety-six subjects used in this study, sixtysix were from the Oregon City school District while thirty were from the Evergreen School District. This represents $68.9 \%$ and $31.3 \%$ of the total population respectively.

Grades one through eleven were represented in this study. The distribution of subjects per mental classification per grade are summarized in Table III in the Appendix.

The ages of the subjects ranged from 6.4 years $(77$ months) to 16.4 years (197 months) with a mean age of 12.4 years (149 months). The mean ages of the normal, borderIine, and mentally deficient subjects were 12.2, 12.1, and 13.0 years respectively. An analysis of variance revealed that there was no significant difference between the mean ages of the three mental classifications. These results are summarized in Table IV in the Appendix.

of the ninety-six subjects, fifty-two (54.2\%) were male while forty-four (45.8\%) were female thus representing an approximately equal number of male and female subjects. The proportion of male and female subjects per mental classification as well as the male-female distribution per 
grade are summarized in Tables $\mathrm{V}$ and VI in the Appendix. Analysis of Test Data

Pearson Product Moment Correlation Coefficients between the Leiter and WISC-R were calculated for each of the mental classifications. These results are shown in Tables VII through $\mathrm{X}$ in the Appendix. Although the correlation between the Leiter and WISC-R Full Scale I.Q. (FSIQ) appears to be high for the normal population $(0.75)$ there appears to be virtually no correlation between the Leiter and WISC-R FSIQ for the borderline (0.01) or mentally deficient (0.11) populations. Additionally, similar correlations were obtained when comparing the Leiter to the WISC-R VIQ and WISC-R PIQ for each mental classification. The only exception occurred when correlating the Leiter with the WISC-R VIQ for the borderline population. The correlation between these scores was a remarkable 0.70 . An analysis of variance was performed on the data to determine whether the Leiter was able to differentiate between the mental classifications. As indicated in Table XI (see Appendix), the WISC-R was able to distinguish quite clearly one mental classification from another. This is as expected since the three mental classifications were an initial premise in the development of the WISC-R. Of note is that both the VIQ and PIQ were each significantly able to distinguish between the three groups. Table XI indicates that the Leiter's ability to distinguish between 
mental classifications approximates that of the WISC-R.

The data also were analyzed from the perspective of WISC-R Verbal-Performance point discrepancies. This information is summarized in Tables XII through XIV in the Appendix. As shown in Figure 1 correlations indicate that as the difference between WISC-R VIQ and PIQ increases toward a 16-20 point difference, the Leiter correlates more highly with all three WISC-R scores (FSIQ, VIQ, and PIQ) until reaching a maximum at $0.77,0.77$, and 0.76 . A downward trend begins at that point. Also of interest, as the Verbal-Performance discrepancy becomes larger, the correlation between the Leiter and VIQ becomes higher than the correlations between the Leiter and the FSIQ or PIQ. It should be noted, however, that these findings may actually be a statistical artifact resulting from an extension of range. Further studies would be necessary to confirm or deny these suspected trends.

A further evaluation of the verbal-performance discrepancy was conducted by identifying the male-female proportions of each discrepancy group. This is summarized in Tables XV and XVI in the Appendix. No significant differences were found. In the analysis of the effect of sex on the WISC-R FSIQ, VIQ, and PIQ and Leiter scores, it was found that sex had neither a significant effect on the scores nor an interaction effect with the mental classification. 


\section{CHAPTER V}

\section{CONCLUSIONS AND RECOMMENDATIONS}

\section{Discussion of the Results}

Review of the results of analysis indicates that the Leiter correlates well with the WISC-R for subjects who fall in the normal range only. It does not correlate well with the WISC-R for borderline or mentally deficient subjects. This supports the suggestions of Beverly and Bensberg (1952), Glenn (1951), and Evans (1954) that the Leiter may not be applicable to mentally deficient subjects in its present form. Since it has already been established by Hunt (1961) that scores on the Leiter are not significantly influenced by whether mentally deficient subjects are brain-injured or of familial cause, this cannot be used as a possible reason for the lack of correlation between the two tests for the mentally deficient population.

In spite of the relatively poor correlation between Leiter and WISC-R IQ scores for the majority of the subjects, analysis of the test data indicated that the Leiter was able to distinguish subjects of one mental classification from another. As shown in Table XI the Leiter appears to be as useful a tool for this purpose as the WISC-R. The results of this study support clegg and White's 
(1966) assertion that sex does not have a significant effect on WISC-R or Leiter scores. This is reinforced in Table XVI. It should be noted that although the normal group was heavily weighted by males and the mentally deficient group was heavily weighted with females, there was a relatively comparable distribution of males and females in the VIQ-PIQ discrepancy groups (Table XII).

of interest is the correlation between the Leiter and WISC-R scores when VIQ-PIQ point discrepancies are considered. The first significant observation with regards to this area of analysis is the fact that twenty-four of this study's ninety-six subjects had a VIQ-PIQ discrepancy of 16 or more points. This discrepancy is evenly distributed between all three mental classifications. As noted by Sattler (1974), the probability of a subject performing so divergently on the two sections of the WISC-R is approximately 1\%. This leads one to believe that either the subjects in this study were extremely unusual or that the frequency of this occurrence is significantly greater than had been initially calculated.

As shown in Figure 1 the Leiter correlates most highly with the WISC-R when there is a 16-20 point difference between the VIQ and PIQ. Since a few of the most common reasons for such a large point difference are reading disorders, visual and/or motor disorders, and some organic dysfunctions, it seems reasonable to suggest that: 
1. The twenty-four subjects in this study who had a 16 or more point difference in their VIQ and PIQ did indeed have some disorder which was reflected in their WISC-R scores.

2. The Leiter may be of significant value when used to evaluate those subjects with the particular disorder(s) exhibited by these subjects.

Consequently, although the Leiter may have little or no value when assessing a borderline or mentally deficient population, it may be of extraordinary value when assessing certain abnormal populations. These specific abnormal populations are not, however, identifiable from this particular study.

\section{Conclusions}

With regards to the questions and hypotheses put forth at the beginning of this paper, it can be concluded that for the combined populations none of the hypotheses suggested could be supported. As shown in Table VII the Leiter did not correlate with any of the WISC-R scores. However, as indicated in Tables VIII through $x$, the Leiter appears to be a valid test when assessing a normal population only. While it may be possible to substitute the Leiter for the WISC-R for a normal subject, it would be inappropriate for a subject suspected of being borderline or mentally deficient.

When considering the question of whether or not the 
Leiter can be used as a substitute for either the verbal or performance sections of the WISC-R, indications are that the Leiter does not consistently correlate well with one section or the other for the total population in this study. Thus, it would be inappropriate to do so without further investigation of this area.

Although this author tended to agree with werner (1965) and Matthews and Birch (1949) that several of the Leiter's subtests appeared to require revision or elimination, this could not be substantiated to any degree of certainty in this study. Further investigation is warranted before such a determination can be made.

Although it was undetermined as to whether the Leiter yielded information which would make it a valuable supplement to the WISC-R, it may be valuable in assessing populations with specific learning and/or organic disorders. These disorders could not be identified in this study. There is little doubt after reviewing the results of this study that there is a significant danger to children who are currently being evaluated with the Leiter and placed in educational and social programs as a result of their performance on this test alone. Although the Leiter is able to differentiate between the various mental classifications, it is possible that many children have been misclassified and, as a result, have received placements unsuitable and possibly detrimental to their levels of cognitive and 
emotional functioning. Further study of the Leiter should be undertaken before it can be recommended that this test can be relied upon to any significant degree.

Suggested Areas for Further

Investigation

Although not substantiated by this study, the Leiter gives the impression of wide applicability and usefulness when testing subjects of all levels of intellectual functioning. Restandardization for use with subjects at the lower end of the I.Q. spectrum appears warranted if the Leiter is to be used with this group.

A further extension of this study would include a more thorough investigation of the individual subtests on the Leiter in terms of the abilities they measure as well as their merit for continued use in the test. Such an analysis would have to take into consideration the age and educational level of each subject analyzed.

The significant correlation between the Leiter and WISC-R when there is a VIQ-PIQ discrepancy of more than 15 points suggests that this population must be studied in greater detail. It may be possible to demonstrate in future studies that subjects with a learning or organic disorder can be accurately assessed with the Leiter. 
Arnold, Gwen F. A technique for measuring the mental ability of the cerebral palsied. Psychological Service Center Journal, 1951, $3,171-1 \overline{78}$.

Arthur, Grace. The Arthur adaptation of the Leiter International performance Scale. Washington, D.C.: Psychological Service Center Press, 1952.

Bensberg, Gerald J., \& Sloan, William. Performance of brain-injured mental defectives on the Arthur adaptation of the Leiter International Performance Scale. Psychological Service Center Journal, 1951, 3, 181184 .

Bessent, Trent E. A note on the validity of the Leiter International Performance Scale. Journal of Consulting Psychology, 1950, 14.

Beverly, Louise, \& Bensberg, Gerald J. A comparison of the Leiter, Cornell-Coxe, and Stanford-Binet with mental defectives. American Journal of Mental Deficiency, $1952, \underline{57}, 89-\overline{91}$.

Birch, Jack W., \& Matthews, Jack. The Leiter International Performance Scale: $A$ suggested instrument in the psychological testing of speech and hearing clinic cases. Journal of Speech and Hearing Disorders, $1949,14,318 .-321$.

Birch, James R., \& Birch, Jack w. The Leiter International Performance Scale as an aid in the psychological study of deaf children. American Annals of the Deaf, 1951, $\underline{96}$.

Birch, Jane R., \& Birch, Jack W. Predicting school achievement in young deaf children. American Annals of the Deaf, 1956, 101.

Birch, Jane R., Stuckles, E. Ross, \& Birch, Jack W. An eleven year study of predicting school achievement in young deaf children. American Annals of the Deaf, $1963, \underline{108}, 236-240$. 
Bloom, Allan S., Raskin, Larry M., \& Reese, Anabel. A comparison of the WISC-R and Stanford-Binet with developmentally disabled children. Psychology in the Schools, 1976,13 .

Clegg, Stanley J., \& White, William F. Assessment of general intelligence of Negro deaf children in a public residential school for the deaf. Journal of Clinical Psychology, 1966, 22, 93-94.

Cooper, James G. Predicting school achievement for bilingual students. Journal of Educational Psychology, $1958, \underline{49}, 31-36$.

Evans, Mildred L. A comparison of the performance of mentally defective children on the Leiter International Performance Scale and the Stanford-Binet. Unpublished Master's Thesis, Pennsylvania State University, 1954.

Gallagher, James J., Benoit, E. Paul, \& Boyd, Herbert F. Measures of intelligence in brain damaged children. Journal of Clinical Psychology, 1956, 12, 69-72.

Glenn, R. T. A comparison of intelligence quotients derived by the Leiter International Performance Scale and the 1937 Stanford revision of the Binet. Unpublished Master's Thesis, University of Pittsburgh, 1951.

Hamm, H., Wheeler, J., McCallum, S., Herrin, M., Hunter, D., \& Catoe, C. A comparison between the WISC and WISC-R among educable mentally retarded students. Psychology in the Schools, 1978, 13, 4-8.

Hunt, Betty M. Differential responses of mentally retarded children on the Leiter Scale. Exceptional Child, $1961, \underline{28}, 99-102$.

Kaufman, A., \& Van Hagen, J. Investigation of the WISC-R for use with retarded children: Correlation with the 1972 Stanford-Binet and comparison of WISC and WISC-R profiles. Psychology in the Schools, 1977, 14, 10-14.

Kaufman, A., \& Weiner, S. A comparison of the WISC-R and WISC for black children aged 7 to 10 years. Paper presented at the annual meeting of the Eastern Psychological Association, Albuquerque, N.M., April 29-30, 1976 .

Larrabee, G. J., \& Holroyd, R. G. Comparison of WISC and WISC-R using a sample of highly intelligent children. Psychological Reports, 1976, 38, 1077-1080. 
Leiter, Russell Graydon. The Leiter International Performance Scale. University of Hawaii Bulletin, 1936, 15.

Leiter, Russell Graydon. The Leiter International Performance Scale: Volume I. Santa Barbara State College Press, Santa Barbara, 1940.

Leiter, Russell Graydon. Part II of the manual for the 1948 revision of the Leiter International Performance Scale. Psychological Service Center Journal, 1950, 2. 259-3 $\overline{43}$.

Matarazzo, Joseph D. Wechsler's measurement and appraisal of adult intelligence. Philadelphia: Williams and Wilkins Company, 1974.

Matthews, Jack, \& Birch, Jack W. The Leiter International Performance Scale: A suggested instrument for psychological testing of speech and hearing clinic cases. Journal of Speech and Hearing Disorders, 1949, 14 .

Mira, Mary P. The use of the Arthur adaptation of the Leiter International Performance Scale and the Nebraska Test of Learning Aptitude with preschool deaf children. American Annals of the Deaf, 1962, 107, 224-228.

Peisner, Earl Frederick. The validity of the Leiter International Performance Scale in measuring the intelli'gence of selected superior children. Doctor's Thesis, Oregon State College (Corvallis, Oregon), 1956.

Sattler, Jerome M. Assessment of children's intelligence. Philadelphia: W. B. Saunders Company, 1974.

Schwarting, F. G. A comparison of the WISC and WISC-R. Psychology in the Schools, 1976, 13, 139-141.

Sharp, Herbert $C$. A note on the reliability of the Leiter International Performance Scale 1948 revision. Journal of Consulting Psychology, 1958, 22, 320 .

Solway, K., Fruge, E., Hays, J. R., Gryll, S., \& Cody, J. Comparison of the WISC and WISC-R scores for juvenile delinquents. Paper presented at the annual meeting of the Southwestern Psychological Association, Albuquerque, N.M., April 29-30, 1976.

Swerdlik, M. E., \& Rice, W. E. WISC minus WISC-R difference for referred children. Unpublished paper, Ingham Intermediate School District, Mason, Michigan, 1975. 
Tate, Miriam E. The influence of cultural factors on the Leiter International Performance Scale. Journal of Abnormal and Social Psychology, 1952, 47, 497-501.

Werner, E. E. Review of the Arthur adaptation of the Leiter International Performance Scale. In 0 . K. Buros (Ed.), The Sixth Mental Measurements Yearbook. Highland Park, N.J.: Gryphon Press, 1965. Pp. 814-816.

Williams, R. W. A clinical examination of the Leiter International Performance Scale. Unpublished Master's Thesis, University of Southern California, 1941.

Wolfe, Willavene, \& Stroud, James B. The contribution of response in mental measurement. Journal of Educational Psychology, 1961, 52.

Zimmerman, I. L. WISC-R minus WISC differences for referred children. Paper presented at the 1975 annual meeting of the American Psychological Association, Chicago, Illinois, 1976. 
APPENDIX 
TABIE III

GRADE DISTRIBUTION

\begin{tabular}{cccccc}
\hline Grade & $\begin{array}{c}\text { Total \# } \\
\text { Subjects }\end{array}$ & \% of Total & \# Normal & \# Borderline & M.D. \\
\hline 1 & 4 & 4.2 & 0 & 1 & 3 \\
2 & 6 & 6.3 & 4 & 1 & 1 \\
3 & 9 & 9.4 & 2 & 4 & 3 \\
4 & 11 & 11.5 & 4 & 5 & 2 \\
5 & 10 & 10.4 & 5 & 3 & 2 \\
6 & 14 & 14.6 & 3 & 6 & 5 \\
7 & 9 & 9.4 & 3 & 3 & 3 \\
8 & 12 & 12.5 & 3 & 3 & 4 \\
9 & 11 & 11.5 & 4 & 0 & 3 \\
10 & 4 & 4.2 & 1 & 2 & 1 \\
11 & 4 & 4.2 & 1 & 0 & 2 \\
Non-Specific/ & & 2.1 & 0 & & \\
Unknown & 2 & & & & \\
\end{tabular}


TABLE IV

AGE DISTRIBUTION

\begin{tabular}{lll|lll|llll}
\hline Age (Months) & $\#$ & 8 & Age (Months) & $\#$ & 8 & Age (Months) & $\#$ & \% \\
\hline 77 & 1 & 1.0 & 131 & 4 & 4.2 & 174 & 4 & 4.2 \\
87 & 1 & 1.0 & 134 & 1 & 1.0 & 175 & 1 & 1.0 \\
90 & 1 & 1.0 & 135 & 3 & 3.1 & 176 & 2 & 2.1 \\
94 & 1 & 1.0 & 137 & 3 & 3.1 & 177 & 1 & 1.0 \\
97 & 2 & 2.1 & 138 & 2 & 2.1 & 179 & 1 & 1.0 \\
98 & 2 & 2.1 & 140 & 1 & 1.0 & 180 & 3 & 3.1 \\
102 & 1 & 1.0 & 141 & 1 & 1.0 & 181 & 1 & 1.0 \\
106 & 1 & 1.0 & 142 & 3 & 3.1 & 182 & 2 & 2.1 \\
108 & 2 & 2.1 & 143 & 1 & 1.0 & 184 & 2 & 2.1 \\
109 & 1 & 1.0 & 144 & 1 & 1.0 & 186 & 2 & 2.1 \\
113 & 2 & 2.1 & 148 & 1 & 1.0 & 187 & 1 & 1.0 \\
118 & 1 & 1.0 & 151 & 1 & 1.0 & 188 & 1 & 1.0 \\
119 & 1 & 1.0 & 152 & 1 & 1.0 & 190 & 2 & 2.1 \\
121 & 1 & 1.0 & 154 & 1 & 1.0 & 191 & 2 & 2.1 \\
122 & 1 & 1.0 & 155 & 1 & 1.0 & 192 & 1 & 1.0 \\
124 & 4 & 4.2 & 161 & 2 & 2.1 & 193 & 1 & 1.0 \\
125 & 1 & 1.0 & 163 & 1 & 1.0 & 194 & 3 & 3.1 \\
126 & 1 & 1.0 & 164 & 2 & 2.1 & 195 & 1 & 1.0 \\
127 & 1 & 1.0 & 166 & 1 & 1.0 & 196 & 1 & 1.0 \\
128 & 1 & 1.0 & 169 & 1 & 1.0 & 197 & 1 & 1.0 \\
129 & 1 & 1.0 & 172 & 1 & 1.0 & & & \\
130 & 1 & 1.0 & 173 & 1 & 1.0 & & & \\
\hline
\end{tabular}

$\begin{array}{lcc} & \text { Mean } & \text { Std. Dev. } \\ \text { Entire Population } & 149.25 & 31.84 \\ \text { Normal } & 146.40 & 31.60 \\ \text { Borderline } & 144.68 & 30.94 \\ \text { Mentally Deficient } & 155.83 & 32.63\end{array}$

ANOVA yields $F=1.192$ with 2 d.f.

This is significant at the $31 \%$ level. Consequently, there is no significant difference between the ages of the various populations. 
TABLE V

MALE-FEMALE PROPORTIONS

$\begin{array}{lcc} & \frac{8 \text { Male }}{54.2} & \frac{8 \text { Female }}{45.8} \\ \text { Entire Sample } & (\mathrm{N}=52) & (\mathrm{N}=44)\end{array}$

\begin{tabular}{|c|c|c|c|c|c|c|}
\hline \multirow[b]{2}{*}{ Mental Classification } & \multicolumn{3}{|c|}{ Males } & \multicolumn{3}{|c|}{ Females } \\
\hline & $\mathrm{N}$ & \% within & $\begin{array}{c}\% \text { Total } \\
\text { Population }\end{array}$ & $\mathrm{N}$ & $\because$ Within & $\begin{array}{c}\& \text { Total } \\
\text { Population }\end{array}$ \\
\hline Normal & 23 & 76.7 & 24.0 & 7 & 23.3 & 7.3 \\
\hline Borderline & 18 & 58.1 & 18.8 & 13 & 41.9 & 13.5 \\
\hline Mentally Deficient & 11 & 31.4 & 11.5 & 24 & 68.6 & 25.2 \\
\hline
\end{tabular}


TABLE VI

DISTRIBUTION OF MALE-FEMALE SUBJECTS

PER GRADE

\begin{tabular}{|c|c|c|c|c|}
\hline \multirow{2}{*}{$\begin{array}{l}\text { School } \\
\text { Grade }\end{array}$} & \multicolumn{2}{|c|}{ Male } & \multicolumn{2}{|c|}{ Female } \\
\hline & No. & 음 & No: & $q$ \\
\hline 1 & 1 & 1.0 & 3 & 3.1 \\
\hline 2 & 4 & 4.2 & 2 & 2.1 \\
\hline 3 & 5 & 5.2 & 4 & 4.2 \\
\hline 4 & 6 & 6.3 & 5 & 5.2 \\
\hline 5 & 7 & 7.3 & 3 & 3.1 \\
\hline 6 & 9 & 9.4 & 5 & 5.2 \\
\hline 7 & 5 & 5.2 & 4 & 4.2 \\
\hline 8 & 7 & 7.3 & 5 & 5.2 \\
\hline 9 & 5 & 5.2 & 6 & 6.3 \\
\hline 10 & 1 & 1.0 & 3 & 3.1 \\
\hline 11 & 1 & 1.0 & 3 & 3.1 \\
\hline Undetermined & 1 & 1.0 & 1 & 1.0 \\
\hline
\end{tabular}


TABLE VII

CORRELATION BETWEEN WISC-R AND LEITER

ENTIRE SAMPLE $(N=96)$

\begin{tabular}{l|c|c|c|c}
\hline & WISC-R(FS) & WISC-R (V) & WISC-R (P) & Leiter \\
\hline WISC-R (FS) & 1.00 & .94 & .95 & .13 \\
WISC-R (V) & .94 & 1.00 & .80 & .15 \\
WISC-R(P) & .95 & .80 & 1.00 & .11 \\
Leiter & .13 & .15 & .11 & 1.00 \\
\hline
\end{tabular}


TABLE VIII

CORRELATION BETWEEN WISC-R AND LEITER

NORMAL SAMPLE ONLY $(N=30)$

\begin{tabular}{l|c|r|r|r}
\hline & WISC-R (FS) & WISC-R (V) & WISC-R (P) & Leiter \\
\hline WISC-R(FS) & 1.00 & .94 & .90 & .75 \\
WISC-R (V) & .94 & 1.00 & .70 & .70 \\
WISC-R(P) & .90 & .70 & 1.00 & .69 \\
Leiter & .75 & .70 & .69 & 1.00 \\
\hline
\end{tabular}


TABLE IX

CORRELATION BETWEEN WISC-R AND LEITER

BORDERLINE SAMPLE $(\mathrm{N}=31)$

\begin{tabular}{l|c|c|c|r}
\hline & WISC-R(FS) & WISC-R (V) & WISC-R (P) & Leiter \\
\hline WISC-R(FS) & 1.00 & .43 & .42 & .01 \\
WISC-R(V) & .43 & 1.00 & -.63 & .70 \\
WISC-R (P) & .42 & -.63 & 1.00 & -.05 \\
Leiter & .01 & .70 & -.05 & 1.00 \\
\hline
\end{tabular}


TABLE $X$

CORRELATION BETWEEN WISC-R AND LEITER

MENTALLY DEFICIENT SAMPLE $(\mathrm{N}=35)$

\begin{tabular}{l|c|c|c|c}
\hline & WISC-R (FS) & WISC-R (V) & WISC-R (P) & Leiter \\
\hline WISC-R (FS) & 1.00 & .62 & .89 & .11 \\
WISC-R (V) & .62 & 1.00 & .20 & .23 \\
WISC-R (P) & .89 & .20 & 1.00 & .04 \\
Leiter & .11 & .23 & .04 & 1.00 \\
\hline
\end{tabular}


TABLE XI

ANALYSIS OF VARIANCE OF WISC-R AND LEITER
MEANS FOR EACH MENTAL CLASSIFICATION

\begin{tabular}{|c|c|c|c|c|c|c|}
\hline Criterion Variable & Population & Range & Mean & S.D. & $F$ & Sig. \\
\hline WISC-R FSIQ & $\begin{array}{l}\text { Entire } \\
\text { Normal } \\
\text { Borderline } \\
\text { Deficient }\end{array}$ & $\begin{array}{l}44-130 \\
80-130 \\
71-79 \\
44-69\end{array}$ & $\begin{array}{l}74.25 \\
94.07 \\
75.00 \\
56.60\end{array}$ & $\begin{array}{r}17.91 \\
13.72 \\
2.79 \\
7.84\end{array}$ & 135.681 & $<1 \%$ \\
\hline WISC-R VIQ & $\begin{array}{l}\text { Entire } \\
\text { Normal } \\
\text { Borderline } \\
\text { Deficient }\end{array}$ & $\begin{array}{l}45-119 \\
68-119 \\
59-85 \\
45-68\end{array}$ & $\begin{array}{l}72.21 \\
90.60 \\
72.23 \\
56.43\end{array}$ & $\begin{array}{r}17.16 \\
15.02 \\
6.15 \\
6.51\end{array}$ & 96.225 & $<18$ \\
\hline WISC-R PIQ & $\begin{array}{l}\text { Entire } \\
\text { Normal } \\
\text { Borderline } \\
\text { Deficient }\end{array}$ & $\begin{array}{l}45-135 \\
78-135 \\
70-93 \\
45-87\end{array}$ & $\begin{array}{l}80.29 \\
98.90 \\
81.35 \\
63.40\end{array}$ & $\begin{array}{r}17.69 \\
12.23 \\
6.50 \\
10.46\end{array}$ & 101.805 & $<1 \%$ \\
\hline Leiter & $\begin{array}{l}\text { Entire } \\
\text { Normal } \\
\text { Borderline } \\
\text { Deficient }\end{array}$ & $\begin{array}{l}42-133 \\
56-133 \\
55-89 \\
42-84\end{array}$ & $\begin{array}{l}82.74 \\
87.83 \\
69.39 \\
56.23\end{array}$ & $\begin{array}{r}18.82 \\
20.04 \\
5.91 \\
8.82\end{array}$ & 43.02 & $<1 \%$ \\
\hline
\end{tabular}


TABLE XII

WISC-R - POINT DIFFERENCE BETWEEN VERBAL AND

PERFORMANCE IQS PER MENTAL CLASSIFICATION

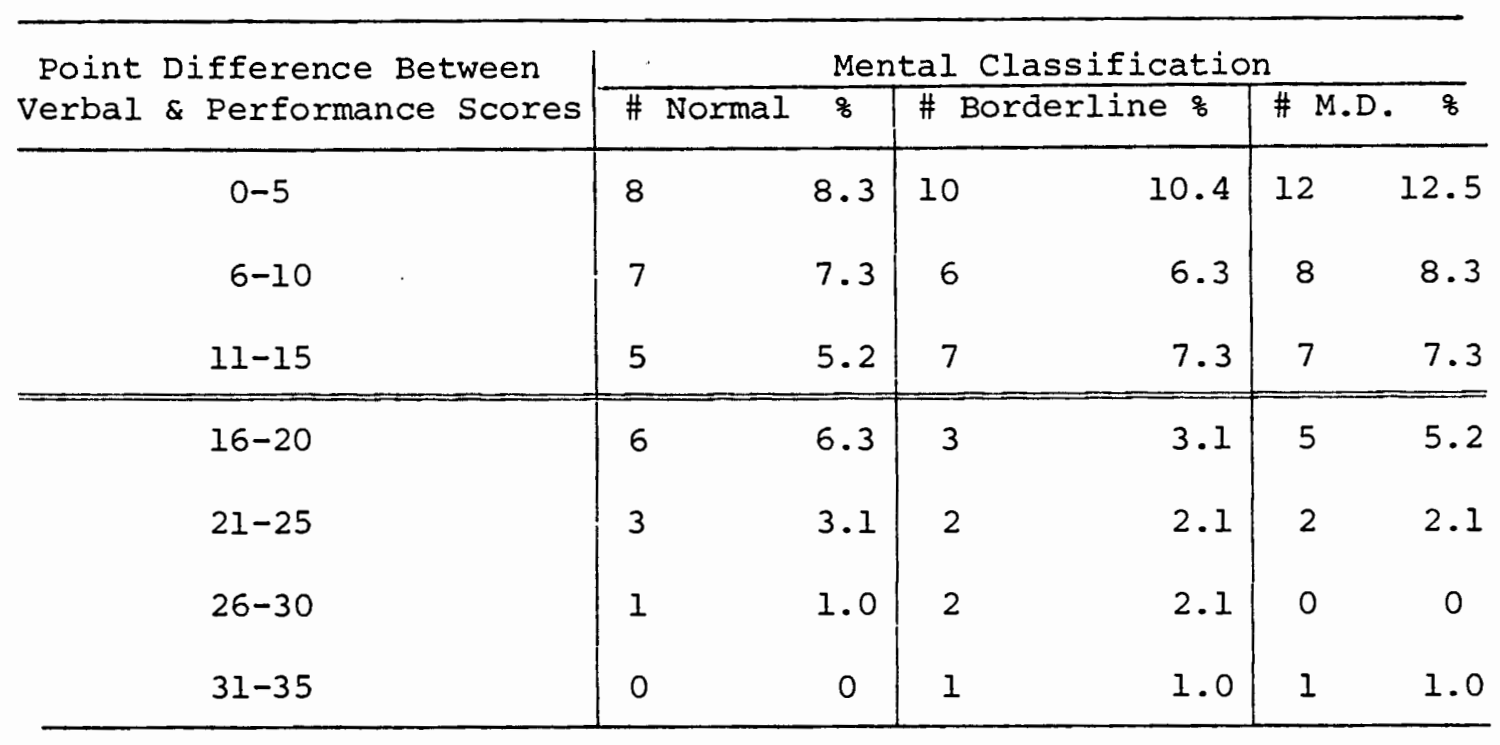


TABLE XIII

CORRELATIONS BETWEEN WISC-R AND LEITER TAKING INTO ACCOUNT POINT DIFFERENCES BETWEEN WISC-R VERBAL AND

PERFORMANCE SCORES (TOTAL POPULATION)

\begin{tabular}{c|ccc}
\hline \multirow{2}{*}{$\begin{array}{c}\text { Point Difference } \\
\text { Between V \& P }\end{array}$} & LIPS \& FS & LIPS \& Verbal & LIPS \& Perf. \\
\hline $0-5$ & 0.08 & 0.07 & 0.10 \\
$6-10$ & 0.14 & 0.12 & 0.15 \\
$11-15$ & 0.76 & 0.74 & 0.69 \\
$16-20$ & 0.77 & 0.77 & 0.76 \\
$21-25$ & 0.71 & 0.73 & 0.69 \\
$26-30$ & -0.44 & -0.50 & -0.21 \\
$31-35$ & Unable to & Unable to & Compute \\
Compute & & & Comple to \\
\hline
\end{tabular}


Figure 1. Graph of correlations between WISC-R and Leiter based on point differences between the WISC-R verbal and performance scores (total population).

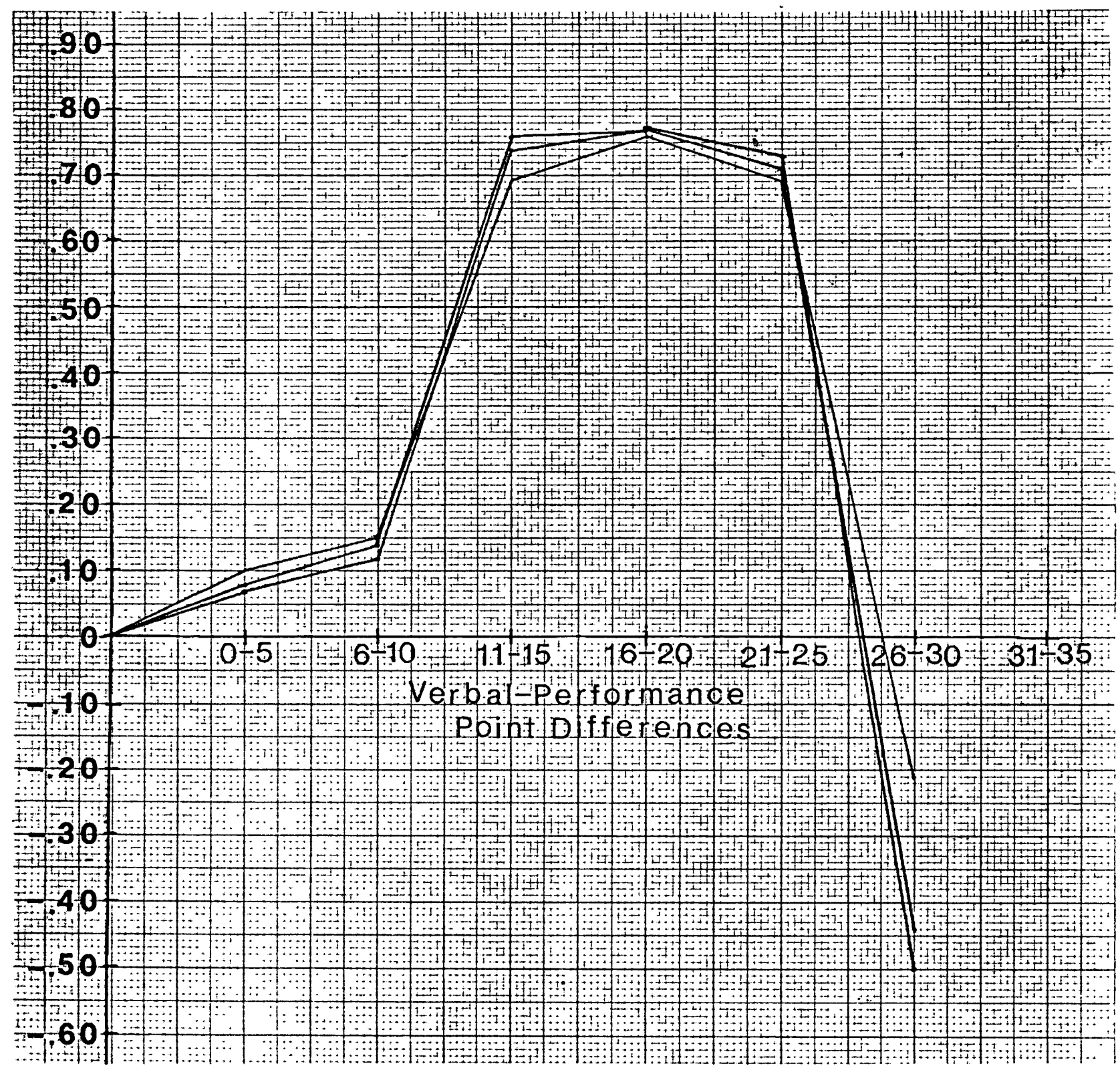

Red - Correlation between LIPS and WISC-R Full Scales.

Blue - Correlation between LIPS and WISC-R VIQ.

Black - Correlation between LIPS and WISC-R PIQ. 
TAELE XIV

CORRELATION OF IEITER TO WISC-R FOR SUBJECTS WITH VERBAL-PERFORMANCE DISCREPANCY

OF 15 POINTS OR LESS

\begin{tabular}{l|ccc}
\hline & Normal & Borderline & Mentally Deficient \\
\cline { 3 - 4 } LIPS \& WISC-R FSIQ & 0.72 & 0.01 & 0.17 \\
LIPS \& WISC-R VIQ & 0.56 & -0.03 & 0.22 \\
LIPS \& WISC-R PIQ & 0.80 & 0.06 & 0.14 \\
\hline
\end{tabular}

CORRELATION OF LEITER TO WISC-R FOR SUBJECTS WITH VERBAL-PEFORMANCE DISCREPANCY

OF MORE THAN 15 POINTS

\begin{tabular}{l|ccc}
\hline & Normal & Borderline & Mentally Deficient \\
\cline { 2 - 4 } LIPS \& WISC-R FSIQ & 0.76 & -0.35 & 0.21 \\
LIPS \& WISC-R VIQ & 0.74 & 0.21 & 0.33 \\
LIPS \& WISC-R PIQ & 0.78 & -0.57 & 0.12 \\
\hline
\end{tabular}


TABLE XV

POINT DIFFERENCES BETWEEN VERBAL AND PERFORMANCE IQS - MALE/FEMALE DIFFEREITTIATION

\begin{tabular}{cccccc}
\hline \multirow{2}{*}{$\begin{array}{c}\text { Point Difference } \\
\text { Between V \& P }\end{array}$} & Male & \multicolumn{3}{c}{ Female } \\
$0-5$ & 15 & 15.6 & 15 & 15.6 \\
$6-10$ & 14 & 14.6 & 7 & 7.3 \\
$11-15$ & 11 & 11.5 & 8 & 8.3 \\
$16-20$ & 5 & 5.2 & 9 & 9.4 \\
$21-25$ & 2 & 2.1 & 5 & 5.2 \\
$26-30$ & 3 & 3.1 & 0 & 0 \\
$31-35$ & 2 & 2.1 & 0 & 0 \\
\hline
\end{tabular}


TABLE XVI

EFFECT OF SEX AND MENTAL CLASSIFICATION ON WISC-R FSIQ, VIQ, PIQ, AND LEITER SCORES

\begin{tabular}{|c|c|c|c|}
\hline Source of Variation & d.f. & $\mathrm{F}$ & Significance of $\mathrm{F}$ \\
\hline Main Effects & 3 & 90.274 & 0.0 \\
\hline Mental Class. & 2 & 113.795 & 0.0 \\
\hline Sex & 1 & 0.207 & 0.650 \\
\hline 2-Way Interactions & 2 & 1.268 & 0.286 \\
\hline Mental Class and Sex & 2 & 1.268 & 0.286 \\
\hline Main Effects & 3 & 63.051 & 0.000 \\
\hline Mental Class. & 2 & 79.013 & 0.0 \\
\hline Sex & 1 & 0.246 & 0.621 \\
\hline 2-Way Interactions & 2 & 0.520 & 0.596 \\
\hline Mental Class and Sex & 2 & 0.520 & 0.596 \\
\hline Main Effects & 3 & 68.061 & 0.000 \\
\hline Mental Class. & 2 & 87.149 & 0.0 \\
\hline Sex & 1 & 0.015 & 0.903 \\
\hline 2-Way Interactions & 2 & 1.619 & 0.204 \\
\hline Mental Class and Sex & 2 & 1.619 & 0.204 \\
\hline Main Effects & 3 & 0.523 & 0.668 \\
\hline Mental Class. & 2 & 0.459 & 0.633 \\
\hline Sex & 1 & 0.234 & 0.628 \\
\hline 2-Way Interactions & 2 & 0.732 & 0.484 \\
\hline Mental Class and Sex & 2 & 0.732 & 0.484 \\
\hline
\end{tabular}

